\title{
Ten Things that Motivational Interviewing Is Not
}

\author{
William R. Miller \\ University of New Mexico, Albuquerque, USA
}

Stephen Rollnick

Cardiff University, School of Medicine, UK

\begin{abstract}
Background: In the 26 years since it was first introduced in this journal, motivational interviewing (MI) has become confused with various other ideas and approaches, owing in part to its rapid international diffusion. Methods: Based on confusions that have arisen in publications and presentations regarding MI, the authors compiled a list of 10 concepts and procedures with which MI should not be addled. Results: This article discusses 10 things that MI is not: (1) the transtheoretical model of change; (2) a way of tricking people into doing what you want them to do; (3) a technique; (4) decisional balance; (5) assessment feedback; (6) cognitive-behavior therapy; (7) client-centered therapy; (8) easy to learn; (9) practice as usual; and (10) a panacea. Conclusion: Clarity about what does (and does not) constitute MI promotes quality assurance in scientific research, clinical practice, and training.
\end{abstract}

Keywords: Motivational interviewing, clinical practice, client-centered, transtheoretical.

\section{Introduction}

It has been 26 years since the first description of motivational interviewing (MI) appeared in this journal. The number of publications on MI has been doubling every 3 years, and there are now MI trainers and translations in at least 38 languages. Within the Motivational Interviewing Network of Trainers (MINT) alone, more than 1,500 people have completed training as MI trainers. If each of them has trained 100 clinicians, and each clinician has practiced MI with 100 people, then at least 15 million people have already been intended recipients of MI as a result of MINT alone.

When a complex method disseminates as widely and rapidly as has happened with MI, it is not surprising that its boundaries become unclear. With the diffusion of any complex innovation (Rogers, 2003) there is a natural process of "reinvention" whereby practitioners adapt the innovation to their own understanding and style. Some such modifications may improve the innovation or render it more accessible for a particular population (Miller, Villanueva, Tonigan and Cuzmar, 2007). It is also possible that reinvention removes some critical elements of the innovation, "active ingredients" in its efficacy. It is therefore important to understand what the

Reprint requests to William Miller, Department of Psychology, University of New Mexico, Logan Hall, Albuquerque, New Mexico NM 87131-1161, USA. E-mail: wrmiller@unm.edu 
essential elements are, and what components can be altered without disrupting the defining nature of a method. Good progress is being made in understanding what makes MI work (Amrhein, Miller, Yahne, Palmer and Fulcher, 2003; Moyers, Miller and Hendrickson, 2005), but clearly there is still a long way to go.

It also sometimes happens that an innovation is altered so fundamentally that it no longer resembles, or is even contradictory to its pristine form. The confrontational, authoritarian and coercive forms of addiction treatment described as "disease model" and "12-step" in the late 20th century were quite at variance with original descriptions of the program of Alcoholics Anonymous (Miller and Kurtz, 1994; White and Miller, 2007). At some point, such a reinvention no longer contains and may even violate the spirit and elements that defined the original approach. This does not necessarily mean that the reinvention is ineffective; merely that it has become something different.

We have sought to define clearly what MI is, and our descriptions have evolved over time (Miller and Rollnick, 1991, 2002; Rollnick, Miller and Butler, 2008; Rollnick and Miller, 1995). We have also offered some contrasts between MI and other approaches. As MI diffuses in practice, we continue to encounter conceptions and descriptions of MI that depart substantially from how we have understood this method. We therefore thought it useful, for clarification and discussion, to describe here 10 things that MI, in our view, is not.

\section{Ten things that MI is not}

\section{MI is not based on the transtheoretical model}

This is an understandable confusion. MI and the transtheoretical model (TTM) of change (Prochaska and DiClemente, 1984) grew up together in the early 1980s. The TTM and its best-known component, the stages of change, revolutionized addiction treatment and more generally how professionals think about facilitating change. Most treatments seem to assume that people are already at least in the preparation or action stage and are ready for change. The TTM popularized a recognition that many if not most people with substance use disorders, even those entering treatment systems, are not yet decided or committed to change, and that interventions should therefore be adjusted to the person's current level of readiness. Rather than blaming people for being unmotivated, it became part of the clinician's task to enhance motivation for change. There were relatively few treatment approaches designed to do that, and so there was a natural fit between MI and the transtheoretical stages of change. Both TTM and MI were presented at the 3rd International Conference on Treatment of Addictive Behaviors in 1984, and the resulting volume was organized around the stages of change (Miller and Heather, 1986). The stages provided a logical way to think about the clinical role of MI, and $\mathrm{MI}$ in turn provided a clear example of how clinicians could help people to move from precontemplation and contemplation to preparation and action.

Nevertheless, MI was never based on the TTM. They are, in essence, kissing cousins who never married. TTM is intended to provide a comprehensive conceptual model of how and why changes occur, whereas MI is a specific clinical method to enhance personal motivation for change. The implicit underlying theory of MI is only now being explicated, and is not intended to be a comprehensive theory of change. It is neither essential nor important to explain the TTM stages of change when delivering MI. It is not necessary to assign people to a stage of change as part of or in preparation for MI. In the second edition of Motivational 
Interviewing, we intentionally removed all reference to TTM in the front (authored) half of the book, precisely because of the extent to which the two were being confused (Miller and Rollnick, 2002). Instead, DiClemente and Velasquez (2002) contributed a chapter to the edited half of the book, specifically exploring the inter-relatedness of TTM and MI.

\section{MI is not a way of tricking people into doing what they don't want to do}

Practitioners sometimes come to an initial MI training expecting to learn a trick for getting people to do what you want them to do in spite of themselves, perhaps analogous to stereotypes of post-hypnotic suggestion or paradoxical intention. Quite to the contrary, MI begins with the assumption and honoring of personal autonomy: that people make their own behavioral choices, and that such power of choice cannot be appropriated by another. Even under the most extreme privations of concentration camps, what could never be taken away was that choice of how to be (Frankl, 1963). If someone genuinely has no inherent motivation for making a change, MI cannot manufacture it. MI is not a sleight of hand for end-running, outwitting, or hijacking an individual's motivation. It is about eliciting the person's own inherent arguments for change, not imposing someone else's. This is true even in the common situation where MI is provided with clients who have been mandated or otherwise coerced to receive treatment. The behavior change involved is one that is in the individual's own interest, not the interests of another person, service, or organization. We believe it would be unethical, for example, to attempt to use MI as a way to sell a product, fill private treatment beds, or obtain consent to participate in research.

Relatedly, MI is not a verb. You don't "MI" someone. Similarly you don't do MI "on" or "to" someone. All of these speech forms imply a kind of expert/recipient relationship that is inconsistent with the underlying assumptions and spirit of MI. The appropriate prepositions are to do MI "for" or "with" someone.

\section{MI is not a technique}

The term "technique" suggests a relatively simple operation, a particular procedure for which there are specific prescribed steps to follow. If MI were a technique, the medical school formula of "See one, do one, teach one" might apply. For better or worse, MI is considerably more complex than this. It is better understood as a clinical or communication method, a complex skill that is learned with considerable practice over time. It is a guiding style for enhancing intrinsic motivation to change (Rollnick et al., 2008).

It was seeing formulaic practice of MI that inspired us first to explicate the underlying assumptions and spirit of MI, without which it is not MI (Rollnick and Miller, 1995). The practice of MI without understanding and manifesting this spirit is like the words without the music of a song. It is missing something essential. Adherence to the spirit of MI is reliably measurable, and predicts treatment outcome (Gaume, Gmel and Daeppen, 2008; Madsón and Campbell, 2006; Miller and Mount, 2001; Moyers, Martin, Catley, Harris and Ahluwalia, 2003; Moyers, Martin, Houck, Christopher and Tonigan, in press). In our earlier writing, however, we gave insufficient attention to this underlying Menschenbild or view of human nature, and this may have contributed to conceptions of MI as a technique.

A related issue here is the use of a structured treatment manual, sometimes assumed to be essential in quality assurance of evidence-based practice. Quality of MI delivery can be 
measured reliably without reference to a particular therapist manual (Madsón and Campbell, 2006). A meta-analysis of MI outcome research (Hettema, Steele and Miller, 2005) found that studies in which there was no specific manual to guide MI yielded double the effect size observed in studies with a structured MI therapist manual, a finding opposite to the usual assumption about the importance of a manual in improving close adherence to a psychotherapeutic method. One clinical trial in which we found virtually no effect of MI on drug use outcomes (Miller, Yahne and Tonigan, 2003) was one in which the therapists followed a highly structured MI manual. Subsequent psycholinguistic analyses suggested the reason why the intervention may have failed to yield the usual effect (Amrhein et al., 2003). Because the MI intervention was limited to one session, the manual required a change plan to be developed at the end of each session. The unspoken instruction was "whether or not the client is ready". For about two-thirds of the sample, this was fine. Language reflecting commitment to change strengthened over the course of the session, and these clients as a group abstained almost completely from drug use over the course of one year of follow-up. The remaining one-third continued to use drugs with high, albeit halved frequency. When Amrhein examined the in-session speech of these less successful clients, he found that strength of commitment to change had dropped back to zero precisely at the point where change planning began. For these clients, it probably would have been better to leave them at the relatively high level of commitment reached through Phase $1 \mathrm{MI}$ rather than insisting that they complete a behavior change plan for which they were not ready. Any clinician skilled in MI who began a change plan and saw the client back-pedaling would not continue pressing for the plan, but these therapists, adhering closely to the manual, went ahead anyhow. The error in the manual was to prescribe a particular sequence of technique, rather than allowing the adaptability that is fundamental to good MI.

MI should not be confused or equated with any of the specific techniques that may be used in service of the clinical method. Importance and confidence ratings, for example, can be used fruitfully within MI, and can be easily taught as a technique for use by health care practitioners who are not necessarily familiar with MI (Rollnick et al., 2008). Collecting such ratings, however, does not constitute MI, nor is it a necessary component of MI.

\section{MI is not a decisional balance}

One technique that has been confused with MI is the constructing of a decisional balance, described long ago by Benjamin Franklin and codified within psychology by Janis and Mann (1977). In this approach for resolving personal conflict and ambivalence, the counselor elicits and thoroughly explores both the pros and the cons of change. Often a 2-by-2 table is constructed enumerating and elaborating (1) the benefits of the status quo, (2) the costs of the status quo, (3) the potential benefits of change, and (4) the potential costs of change. Thoroughly exploring both sides of the equation is thought to help people clarify and rationally resolve their ambivalence. We believe that this approach is entirely appropriate when the counselor wants to avoid advocating for change or tipping the balance in a particular direction.

We did briefly mention one potential use of a decisional balance technique in MI (Miller and Rollnick, 1991, 2002). It was one of a range of eight strategies that we described for eliciting change talk. Particularly for clients who are much earlier in readiness for change, who offer relatively few arguments for change and appear more resistant, this can be one way of getting a running head start. Asking first about the good things about drinking then affords 
some leverage and naturalness to ask about the not-so-good side as well. It is not a method that we would use routinely, but rather with clients for whom initial attempts to elicit pro-change arguments meet with little success. In some representations of MI, however, the constructing of a full decisional balance became a prescribed, essential, even defining technique. Doing a 2- or 4-sided discussion of the pros and cons was sometimes itself considered to be MI.

There is nothing fundamental, essential, or definitive about the decisional balance technique in the practice of MI. In fact, it could be contraindicated within our original conception of MI, wherein the focus is on eliciting the client's own change talk and taking care not to reinforce counter-change talk. The client's counter-change motivations do naturally come up in MI with ambivalent people. We have described a variety of ways to respond to such "sustain talk" (formerly subsumed under "resistance") so as not to continue to elicit and strengthen it, and to bring the conversation back to change talk. The reservation that we have about the decisional balance technique is that it goes hunting for sustain talk, intentionally elicits and explores it. Roughly equal exploration is given to arguments on both sides of the equation. From our perspective, the ambivalent person was already there: immobilized by counterbalancing pros and cons that cancel each other out. From the very first description of MI (Miller, 1983), it has been about selectively eliciting and reinforcing the client's own arguments and motivations for change. In MI, people are literally talking themselves into change (Miller and Rollnick, 2004). Within this perspective, it makes little sense to intentionally elicit and give equal air time and attention to the counter-change arguments.

Again, we are not saying that it is wrong to construct a decisional balance. It is a welldescribed technique that may be effective in pursuing certain clinical goals. We have used it in helping people to see their dilemma clearly and to make a conscious and willful choice of direction when we wanted to avoid influencing the direction of choice. There are also certain circumstances, as described above, when it may be useful within MI. Our point is that decisional balance is a technique and not MI, and if used routinely may even work against the principles and aims of MI.

\section{MI does not require assessment feedback}

This confusion traces back to the Project MATCH Research Group (1993) in which we had the task of selecting and designing three therapies to be compared in the treatment of alcohol dependence. It was a foregone conclusion that at least one of the three would be Cognitive Behavior Therapy (CBT), since that was the theoretical orientation of virtually every principal investigator in the trial. A Twelve-Step Facilitation (TSF) therapy was also chosen to mirror what was then a widespread approach in US alcoholism treatment. For the third approach, outcome trials provided solid evidence for the efficacy of brief interventions, and MI was a well-described clinical method with a therapeutic rationale different from either CBT or TSF. Because both CBT and TSF were planned as 12-session treatments over a span of 12 weeks, there was reluctance to compare them with a 1- or 2-session treatment because it would confound modality with intensity. Nevertheless, it made little sense to have a 12-session brief intervention. As a compromise, the research group settled on an MI-based treatment consisting of four sessions spread over 12 weeks. To expand content of the initial sessions, we added to MI the use of structured personal feedback of findings from intake assessment. Miller had earlier described this combination as the "drinker's check-up", which was a single session of counseling following assessment (Miller, Benefield and Tonigan, 1993; 
Miller and Sovereign, 1989). This 4-session Project MATCH intervention was given the name "Motivational Enhancement Therapy" (MET; Miller, Zweben, DiClemente and Rychtarik, 1992).

Feedback from structured assessment can be useful in itself (Agostinelli, Brown and Miller, 1995). Particularly with people who evidence less initial motivation for change ("precontemplation" within the TTM), such feedback can provide topics for discussion in MI, and often uncovers potential reasons for change that had not been evident before. Assessment feedback, however, is not an inherent or essential element in MI, nor does providing such feedback constitute MI. The clinical style of MI can proceed with or without assessment findings and feedback, which are neither necessary nor sufficient for MI. MET is the particular combination of the clinical style of MI with structured assessment feedback.

\section{MI is not a form of cognitive-behavior therapy}

Miller's predoctoral training at the University of Oregon certainly emphasized cognitivebehavior therapies, though he also learned the client-centered counseling methods of Carl Rogers. More than any of these, he was trained in pragmatic empiricism - to believe the data, to follow findings wherever they might lead. It was precisely unexpected results in treatment studies that led to the doorstep of MI.

The initial description of the clinical method of MI was not derived from a theoretical base. Instead it arose as Norwegian colleagues evoked from Miller some tacit decision rules that he had been using intuitively in clinical practice, implicit principles of which he had not been aware, and that did not correspond particularly well with the cognitive-behavioral approaches he was teaching at the time (Moyers, 2004). Although he made some post-hoc linkages to certain social psychological theories such as cognitive dissonance, reactance, and self-perception theory (Miller, 1983), MI was not the product of rational deduction from such theories. Rather it represented a clinical method, and later a growing body of empirical findings, in need of theoretical explanation.

Cognitive-behavior therapies generally involve providing clients with something that they are presumed to lack. The missing piece might be new coping skills, conceptual education about how behavior is learned, counterconditioning, environmental contingencies, or the restructuring of faulty cognitions toward more adaptive ones. The expertise of CBT providers rests on their knowledge of and technical skill in applying principles of learning. The typically brief course of MI in one or two sessions does not involve teaching new skills, re-educating, counterconditioning, changing the environment, or installing more rational and adaptive beliefs. It is not about installing anything, but rather is about eliciting from people that which is already there. It is not the communication of an expert who assumes that "I have what you need", but rather the facilitative style of a companion whose manner says, "You have what you need, and together we'll find it." Neither is MI fundamentally cognitive therapy, with the clinician correcting erroneous client beliefs. There are substantial emotional bases to MI (Wagner and Ingersoll, 2008), and its conceptual framework, its underlying spirit, is fundamentally humanistic rather than behaviorist.

\section{MI is not just client-centered counseling}

Is MI, then, merely a reincarnation of Rogerian counseling under another name? Certainly the insights and methods of Carl Rogers are foundational to the practice of MI, and its development 
has been much advanced through the psychotherapy process and outcome research methods pioneered by Rogers and his students. The "critical conditions for change" outlined by Rogers (1959) are similar to the definitive "spirit of MI" that we have described (Miller and Rollnick, 2002; Rollnick and Miller, 1995). In a way, MI is an evolution of client-centered counseling.

MI departs from traditional conceptions of client-centered counseling, however, in being consciously goal-oriented, in having intentional direction toward change. In MI, the counselor strategically listens for, elicits, and responds selectively to certain forms of speech that are collectively termed "change talk." Over the course of an MI session, the counselor seeks to increase the client's strength of expressed motivation for a target behavior change, and to diminish defenses of the status quo. Such differential reinforcement of particular forms of client speech was anathema to Carl Rogers, although his student Truax (1966) published findings suggesting that this is precisely what Rogers was doing in his own counseling.

A typical result of client-centered counseling is that the client speaks much more than the counselor does, and offers a wide array of material from which the counselor must select what to reflect, what to ask more about, and what to include in summaries. The only common guidance given for this selection process within client-centered counseling was to focus in particular on feelings expressed or present but unspoken. MI offers a clear rationale and guidelines regarding forms of speech that lead to behavior change, and how to evoke and strengthen such client language.

\section{MI is not easy}

MI is simple but not easy. This is true of the foundational client-centered skill of accurate empathy (reflective listening), as well as for the broader clinical method of MI. Watch a skillful clinician providing MI, and it looks like a smoothly flowing conversation in which the client happens to become increasingly motivated for change. In actual practice, MI involves quite a complex set of skills that are used flexibly, responding to moment-to-moment changes in what the client says. Learning MI is rather like learning to play a complex sport or a musical instrument. Going to an initial 2-day training can provide a certain head start, but real skill and comfort grow through disciplined practice with feedback and coaching from a knowledgeable guide. We are invited sometimes to teach MI during a 2-hour "workshop" or even during lunch while a pharmaceutical firm provides the pizza. Think of a similar invitation to teach the viola, or tennis, or for that matter psychoanalysis, over lunch! MI is not a trick or a technique that is easily learned and mastered. It involves the conscious and disciplined use of specific communication principles and strategies to evoke the person's own motivations for change. Training research indicates that proficiency in MI is not readily developed through self-study or by attending a workshop, but typically requires practice with feedback and coaching over

time (Miller, Yahne, Moyers, Martinez and Pirritano, 2004), which appears to be true more generally of complex evidence-based treatments (Miller, Sorensen, Selzer and Brigham, 2006).

\section{MI is not what you were already doing}

Given the above, we believe it is difficult for clinicians to find their way naturally and intuitively into this particular therapeutic approach without specific training. "I already do that" seems to be a common comment on initial exposure to MI. "Sure I motivate my patients. Of course I 
listen to them!" We have found, however, near-zero correlations of clinicians' self-perceived competence in reflective listening and in MI with their actual observed proficiency in practice samples (Miller and Mount, 2001; Miller et al., 2004). An early study found that attending a 2-day workshop convinced clinicians that they had learned MI and did not need further training, whereas their practice samples showed insufficient change to make any difference for their clients (Miller and Mount, 2001).

Nevertheless, some clinicians do seem to "recognize" MI when they first encounter it, which suggests some common elements with their intuitive practice. We have described MI as being a refined form of the naturally-occurring communication style of guiding when helping someone to solve a problem (Rollnick et al., 2008). Guiding involves a flexible blend of informing, asking and listening, and skillful clinicians do this in practice, as do good parents and teachers. As such, MI resembles a familiar approach to helping, but in a refined manner that uses reflective listening in guiding the person to resolve ambivalence about behavior change. Learning MI involves retaining clarity of purpose and calmness in the face of often irrational and seemingly contrary motives, and using thoughtful reflective listening statements to facilitate change.

\section{MI is not a panacea}

Finally, MI was never meant to be a "school" of psychotherapy or a comprehensive approach to treatment. It is a particular tool for addressing a specific problem: when a person may need to make a behavior or lifestyle change and is reluctant or ambivalent about doing so. Rogers' client-centered counseling was developed as a broad theory of and approach to change, and one could center an entire psychotherapy practice around his method. It would make little sense, however, to have a practice that offers only MI. It is clearly not intended to address all situations and problems that are presented to a health professional. People who are already ready for change do not need MI, and there is some evidence that it may slow down their progress relative to action-oriented treatment (Project MATCH Research Group, 1997; Rohsenow et al., 2004; Stotts, Schmitz, Rhoades and Grabowski, 2001). Neither would MI itself be used to help people make a life choice for which the clinician has no business tipping the balance one way or the other, precisely because MI was designed to favor resolution of ambivalence in a particular direction. MI can, however, be combined with a variety of other treatment methods, and there is evidence that doing so increases the clinical impact of both (Hettema et al., 2005).

Relatedly, MI is a relatively brief intervention. In order to stretch it to fill four sessions, the Project MATCH group added structured assessment feedback and two follow-up sessions to form MET (Miller et al., 1992). Ordinarily, within the 50-minute hour tradition of psychotherapy, we would not expect MI to fill more than a session or two. If individuals are not moving in the direction of change, it makes no sense to deliver 16 sessions of MI, as if by persistence to wear them down. MI explicitly honors autonomy, people's right and irrevocable ability to decide about their own behavior. In shorter consultations, as in health care, the delivery of MI may occur in briefer periods over time, again with the purpose of exploring and mobilizing the person's own intrinsic motivations for change. We are asked sometimes, "Can you do MI in five minutes?" To us that is like the question, "Can you play the piano for five minutes?" Of course you can. It is a different question whether that "dose" of MI will be a sufficient catalyst for behavior change, but the literature contains a number of 
positive trials of MI with relatively brief duration (Hettema et al., 2005). At the upper end, as with a piano concert, we expect that 2-3 hours of MI is about as much as people will tolerate.

\section{So What Is Motivational Interviewing?}

Having differentiated MI from 10 things with which it is sometimes confused, we offer an updated definition of what it is. Motivational interviewing is a collaborative, person-centered form of guiding to elicit and strengthen motivation for change.

\section{Discussion}

To be sure, motivational interviewing is a living, evolving method. In response to both clinical experience and emerging research, the ways in which we think about and describe MI have changed. Relative to our early explications, for example, we now give greater emphasis to the underlying spirit of MI. As a result of Amrhein's psycholinguistic analyses, we have changed the way in which we conceptualize change talk, and differentiate its opposite - sustain talk from resistance. The ways in which we train clinicians and trainers have changed significantly over the years, and more than 180 published clinical trials have clarified the applications and limitations of MI.

From the beginning, we have intentionally avoided trademarking, copyrighting licensing, restricting, or policing the use of MI. The method is now so widely used that it is beyond anyone's ownership. The Motivational Interviewing Network of Trainers more generally has been inclined toward open sharing of its materials and insights rather than protecting ideas and trade secrets.

This choice comes with a cost. There has been no inherent quality control or accountability in the practice and training of MI. Rapid diffusion incurs the risk of a method becoming diffuse. The understanding of what constitutes MI can change down a chain of communication, much like the children's game of whisper-down-the-line. New understandings find their way into practice and writing, even without realization that they are revisions. Other descriptions and adaptations, including our own, have introduced new terms for closely related practices (Botelho, 2004; Miller et al., 1992; Rollnick, Mason and Butler, 1999; Tober and Raistrick, 2007). All of this can create public and professional confusion regarding a clinical method.

In one sense, it doesn't matter. Brand name therapies come and go, each containing kernels of truth as well as superfluous elements. The science of clinical psychology advances by coming to understand robust as well as subtle principles of change that can be reliably applied in the alleviation of human suffering. Understanding these principles helps us to know what is truly important in therapeutic adherence.

The vagaries of a treatment, however, can also impair scientific understanding. The specific efficacy of a treatment method is more difficult to detect when its delivery is highly variable. This is equally true of "nonspecific" or "common" factors that are hypothesized to have important impact on treatment outcome. MI is a particular treatment method with a rather encouraging base of evidence for efficacy. The variability of outcomes across trials, sites, and therapists argues all the more for being clear about exactly what does and does not constitute this treatment method. There are negative trials in the literature where the "MI" being tested bears little apparent resemblance to the clinical method that we have described (e.g. Kuchipudi, Hobein, Fleckinger and Iber, 1990). In this regard, being clear what is meant when MI is being delivered is important. Professional consensus on the boundaries and competencies of a 
specific clinical method can also serve to protect the public when seeking help from a particular evidence-based treatment. In this regard, we hope that our observations will be useful.

\section{References}

Agostinelli, G., Brown, J. M. and Miller, W. R. (1995). Effects of normative feedback on consumption among heavy drinking college students. Journal of Drug Education, 25, 31-40.

Amrhein, P. C., Miller, W. R., Yahne, C. E., Palmer, M. and Fulcher, L. (2003). Client commitment language during motivational interviewing predicts drug use outcomes. Journal of Consulting and Clinical Psychology, 71, 862-878.

Botelho, R. (2004). Motivational Practice: promoting healthy habits and self-care of chronic diseases. Rochester, NY: MHH Publications.

DiClemente, C. C. and Velasquez, M. W. (2002). Motivational Interviewing and the stages of change. In W. R. Miller and S. Rollnick (Eds.), Motivational Interviewing: preparing people for change. (2nd ed., pp. 217-250). New York: Guilford Press.

Frankl, V. E. (1963). Man's Search for Meaning. Boston: Beacon Press.

Gaume, J., Gmel, G. and Daeppen, J.-B. (2008). Brief alcohol interventions: do counsellors' and patients' communication characteristics predict change? Alcohol and Alcoholism, 43, 62-69.

Hettema, J., Steele, J. and Miller, W. R. (2005). Motivational interviewing. Annual Review of Clinical Psychology, 1, 91-111.

Janis, I. L. and Mann, L. (1977). Decision Making: a psychological analysis of conflict, choice and commitment. New York: Free Press.

Kuchipudi, V., Hobein, K., Fleckinger, A. and Iber, F. L. (1990). Failure of a 2-hour motivational intervention to alter recurrent drinking behavior in alcoholics with gastrointestinal disease. Journal of Studies on Alcohol, 51, 356-360.

Madsón, M. B. and Campbell, T. C. (2006). Measures of fidelity in motivational enhancement: a systematic review. Journal of Substance Abuse Treatment, 31, 67-73.

Miller, W. R. (1983). Motivational interviewing with problem drinkers. Behavioural Psychotherapy, 11, 147-172.

Miller, W. R., Benefield, R. G. and Tonigan, J. S. (1993). Enhancing motivation for change in problem drinking: a controlled comparison of two therapist styles. Journal of Consulting and Clinical Psychology, 61, 455-461.

Miller, W. R. and Heather, N. (Eds.). (1986). Treating Addictive Behaviors: processes of change. New York: Plenum Press.

Miller, W. R. and Kurtz, E. (1994). Models of alcoholism used in treatment: contrasting A.A. and other perspectives with which it is often confused. Journal of Studies on Alcohol, 55, 159-166.

Miller, W. R. and Mount, K. A. (2001). A small study of training in motivational interviewing: does one workshop change clinician and client behavior? Behavioural and Cognitive Psychotherapy, 29, 457-471.

Miller, W. R. and Rollnick, S. (1991). Motivational Interviewing: preparing people to change addictive behavior. New York: Guilford Press.

Miller, W. R. and Rollnick, S. (2002). Motivational Interviewing: preparing people for change (2nd ed.). New York: Guilford Press.

Miller, W. R. and Rollnick, S. (2004). Talking oneself into change: motivational interviewing, stages of change, and the therapeutic process. Journal of Cognitive Psychotherapy, 18, 299-308.

Miller, W. R., Sorensen, J. L., Selzer, J. and Brigham, G. (2006). Disseminating evidence-based practices in substance abuse treatment: a review with suggestions. Journal of Substance Abuse Treatment, 31, 25-39. 
Miller, W. R. and Sovereign, R. G. (1989). The check-up: a model for early intervention in addictive behaviors. In T. Løberg, W. R. Miller, P. E. Nathan and G. A. Marlatt (Eds.), Addictive Behaviors: prevention and early intervention (pp. 219-231). Amsterdam: Swets and Zeitlinger.

Miller, W. R., Villanueva, M., Tonigan, J. S. and Cuzmar, I. (2007). Are special treatments needed for special populations? Alcoholism Treatment Quarterly, 25, 63-78.

Miller, W. R., Yahne, C. E., Moyers, T. B., Martinez, J. and Pirritano, M. (2004). A randomized trial of methods to help clinicians learn motivational interviewing. Journal of Consulting and Clinical Psychology, 72, 1050-1062.

Miller, W. R., Yahne, C. E. and Tonigan, J. S. (2003). Motivational interviewing in drug abuse services: a randomized trial. Journal of Consulting and Clinical Psychology, 71, 754-763.

Miller, W. R., Zweben, A., DiClemente, C. C. and Rychtarik, R. C. (1992). Motivational Enhancement Therapy Manual: a clinical research guide for therapists treating individuals with alcohol abuse and dependence (Vol. Project MATCH Monograph Series, Vol. 2). Rockville, Maryland: National Institute on Alcohol Abuse and Alcoholism.

Moyers, T. B. (2004). History and happenstance: how motivational interviewing got its start. Behavioural and Cognitive Psychotherapy, 19, 291-298.

Moyers, T. B., Martin, T., Catley, D., Harris, K. J. and Ahluwalia, J. S. (2003). Assessing the integrity of motivational interventions: reliability of the Motivational Interviewing Skills Code. Behavioural and Cognitive Psychotherapy, 31, 177-184.

Moyers, T. B., Martin, T., Houck, J. M., Christopher, P. J. and Tonigan, J. S. (in press). From in-session behaviors to drinking outcomes: a causal chain for motivational interviewing. Journal of Consulting and Clinical Psychology.

Moyers, T. B., Miller, W. R. and Hendrickson, S. M. L. (2005). How does motivational interviewing work? Therapist interpersonal skill predicts client involvement within motivational interviewing sessions. Journal of Consulting and Clinical Psychology, 73, 590-598.

Prochaska, J. O. and DiClemente, C. C. (1984). The Transtheoretical Approach: crossing traditional boundaries of therapy. Homewood, Illinois: Dow/Jones Irwin.

Project MATCH Research Group (1993). Project MATCH: rationale and methods for a multisite clinical trial matching patients to alcoholism treatment. Alcoholism: Clinical and Experimental Research, 17, 1130-1145.

Project MATCH Research Group (1997). Project MATCH secondary a priori hypotheses. Addiction, 92, 1671-1698.

Rogers, C. R. (1959). A theory of therapy, personality, and interpersonal relationships as developed in the client-centered framework. In S. Koch (Ed.), Psychology: the study of a science. Vol. 3. Formulations of the Person and the Social Contexts (pp. 184-256). New York: McGraw-Hill.

Rogers, E. M. (2003). Diffusion of Innovations (5th ed.). New York: Free Press.

Rohsenow, D. J., Monti, P. M., Martin, R. A., Colby, S. M., Myers, M. G., Gulliver, S. B., Brown, R. A., Mueller, T. I., Gordon, A. and Abrams, D. B. (2004). Motivational enhancement and coping skills training for cocaine abusers: effects on substance use outcomes. Addiction, 99, 862874.

Rollnick, S., Miller, W. R. and Butler, C. C. (2008). Motivational Interviewing in Health Care. New York: Guilford Press.

Rollnick, S., Mason, P. and Butler, C. (1999). Health Behavior Change: a guide for practitioners. Oxford: Churchill Livingstone.

Rollnick, S. and Miller, W. R. (1995). What is motivational interviewing? Behavioural and Cognitive Psychotherapy, 23, 325-334.

Stotts, A. L., Schmitz, J. M., Rhoades, H. M. and Grabowski, J. (2001). Motivational interviewing with cocaine-dependent patients: a pilot study. Journal of Consulting and Clinical Psychology, 69, $858-862$. 
Tober G. and Raistrick D. (Eds.) (2007). Motivational Dialogue: preparing addiction professionals for motivational interviewing practice. London: Routledge.

Truax, C. B. (1966). Reinforcement and non-reinforcement in Rogerian psychotherapy. Journal of Abnormal Psychology, 71, 1-9.

Wagner, C. C. and Ingersoll, K. S. (2008). Beyond cognition: broadening the emotional base of motivational interviewing. Journal of Psychotherapy Integration, 18, 191-206.

White, W. L. and Miller, W. R. (2007). The use of confrontation in addiction treatment: history, science, and time for a change. The Counselor, 8, 12-30. 